Modernism and Coherence - Four chapters of a negative aesthetics. Fabio Alkcelrud Durão (Frankfurt: Peter Lang, 2008)

\title{
CONFRONTOS ENTRE SENTIDO E RESISTÊNCIA
}

Para Adorno, a arte configura-se como uma forma de saber oposta ao conhecimento da razão instrumental, cujos conceitos, categorias e métodos buscam infligir ao mundo administrado certa coerência. Contudo, é justamente na arte que a tese de insuficiência do conceito estabelece-se de forma mais contundente, ao firmar-se como instância ininteligível e refutar uma lógica coerente e coercitiva imposta por regras e paradigmas da razão instrumental. É nessa conjuntura que podemos inscrever o livro Modernism and Coherence: Four chapters of a negative aesthetics, de Fabio Akcelrud Durão, professor do Departamento de Teoria Literária do IEL/Unicamp. A partir de um extenso e fundamentado exame da crítica conferida às obras de T. W. Adorno, Wallace Stevens, Robert Frost e James Joyce, Durão intenta suscitar momentos de resistência, silenciamentos e indeterminação decorrentes do confronto entre essas obras e sua fortuna crítica. Os quatro capítulos que compóem o livro - precedidos por uma elaborada discussão que problematiza a própria postulação teórica da estética negativa e seu caráter aporético como gesto de sistematização epistemológica - apresentam-se como instâncias elucidativas nas quais o confronto da crítica com os textos geradores evidencia ainda mais suas indeterminações, dissonâncias e recusas de interpretação.

Partindo do princípio de que uma conceitualização sistemática da estética negativa, como gesto de refutação interpretativa, só pode ser pensada mediante uma confrontação processual de leituras e críticas já existentes, o capítulo inicial suplanta a mera e típica explanação dos principais postulados da estética negativa - abordagem comum a esse tipo de trabalho - para construir uma argumentação pautada no cotejo da obra de Adorno em relação tanto a textos que objetivam sua exegese quanto a estudos congêneres. Nesse sentido, a mediação estabelecida entre os aspectos da negatividade pensada por Adorno, contraposta aos trabalhos de outros teóricos, como a exemplo de Derrida, caracteriza-se como uma forma notável de configurar a estética negativa em um panorama não apenas 
mais amplo e complexo, mas também mais hodierno. Tal abordagem, à medida que confere um caráter dialético à construção argumentativa da temática em questão, resulta também em um ponto de equilíbrio; isto é, não produz uma discussão demasiadamente hermética para o leitor não iniciado na obra de Adorno, mas, ao mesmo tempo, também não incorre no risco de conferir-lhe uma impensável estruturação conceitual. Por sua vez, a escolha de produzir um estudo pautado nas relaçóes entre negatividade e modernismo deve-se ao fato de que esse se caracterizou como um período especialmente profícuo ao exercício de elucidação da negatividade e indeterminação, engendrada em seu confronto com a crítica. Esse, aliás, é um aspecto central para se compreender Modernism and Coherence, posto que, além de trazer em seu bojo o limiar da ambiguidade, a produção estética modernista parece estar mais isenta de problemas gerados por abordagens interpretativas que requerem por demais uma explanação conceitual. Com efeito, ao apontar os aspectos basilares para se compreender a negatividade e problematizá-la no confronto com a leitura de textos e obras literárias, sem, ao mesmo tempo, deixar de assinalar seus os pontos de proximidade e divergência com outras sistematizações hermenêuticas, o capítulo inicial já acena para uma forma de elaboração argumentativa dialética que se desenvolverá nas seções seguintes.

No primeiro dos quatro ensaios acerca da negatividade e indeterminação - e com o sugestivo título "Aesthetic Theory as Whirlpool: an anti-argumentative approach"-, é a própria Teoria Estética de Adorno que, longe de qualquer intencionalidade autoral, desempenha o papel de objeto de estudo daquilo que teoriza, despontando como uma instância na qual toda tentativa de um gesto interpretativo resulta paradoxalmente em uma contínua deferência do sentido. O escrutínio, tanto de textos que objetivam uma exegese da obra em questão quanto de outros textos do próprio Adorno, evidencia na estrutura sua circular da Teoria Estética, à medida que categorias são apresentadas, repetidas e recapituladas sob diferentes configurações e, consequentemente, significados. Ademais, ao serem confrontadas com tentativas de significação, tais categorias e conceitos obscurecem ainda mais os elementos-chave tanto no pensamento quanto na escrita de Adorno - caracterizada por descontinuidades argumentativas, que acentuam ainda mais a natureza antipredicativa dessa obra. Logo, o que se observa é que o próprio livro do filósofo frankfurtiano, notório por sua estrutura densa e com uma 
escrita que abarca, ao mesmo tempo, o discurso acadêmico e literário, engendra um tipo de autorreferencialidade, tornando-se objeto daquilo que disserta. Salutar também é constatação, ao final desse capítulo, de que, devido a essa peculiar característica, o texto oscila entre uma teoria estética, ou ainda uma teoria estética.

O capítulo seguinte, denominado "The Pressure of Reality and the Escape Valve of Truth", parte do pressuposto de que a poesia de Wallace Stevens possibilita um espaço profícuo para aferição de gestos que teçam uma interpretação coesa de obras modernistas pelo confronto entre poesia e sociedade - no caso, a sociedade americana das primeiras décadas do século XX -, em um contexto fortemente marcado pela pressão da realidade. Durão enfatiza aqui a questão da experiência, posto que esta é então pensada em relação à função da imaginação na poesia. Desse modo, a problemática da imaginação, como o recurso mais notório para se pensar uma válvula de escape diante das pressões demandadas pela realidade, é tratada em três momentos distintos: no primeiro, a ênfase de uma crítica pautada em um Stevens biográfico finda por conferir à imaginação um caráter compensatório; em um segundo momento, e sob o escrutínio teórico do próprio Stevens, que arrisca uma teorização sobre sua produção, tanto a poesia quanto seu aspecto imaginativo são concebidos como um meio de reconciliação; isto é, uma espécie de cimento ficcional que intenta por um fim ao antagonismo e ao conflito social impostos pela pressão da realidade sob a imaginação. $\mathrm{O}$ que se observa, de modo mais evidente nesses dois momentos, é que a contínua ênfase da crítica no caráter imaginativo da poesia de Stevens surte efeito contrário ao do intentado, esvaziando-a de sentido, posto que o próprio conceito de imaginação advém de construtos sócio-históricos e, por conseguinte, traz em seu cerne tais antagonismos e contradições. $\mathrm{O}$ terceiro momento de exegese refere-se ao modo como alguns poemas de Stevens, em particular, incorporam a pressão da realidade e a ela respondem. Durão constrói sua argumentação tendo como base o poema "On the road home", interpretado de acordo com quatro círculos concêntricos e sucessivos de coerência: argumentativo, imagístico, dêitico e sonoro. Aqui o minucioso exame do poema, através de leitura cerrada (close reading), demonstra o modo como uma abordagem interpretativa não é fechada em si, mas finda por apontar para uma miríade de possibilidades interpretativas. Contudo, é, justamente, no elemento da sonoridade, mais preci- 
samente na irreconciliabilidade entre som e sentido, que o poema de Stevens encontra uma válvula de escape da pressão da realidade, à medida que, ao refutar uma unidade sentido, acena para sua impossibilidade de completude.

O mote do capítulo sobre a poesia de Robert Frost, intitulado "The Poem Ahead of You", discute as vicissitudes da negatividade face à problemática do espaço. $\mathrm{O}$ exame que Durão faz da recepção crítica da obra do aclamado poeta norte-americano demonstra um intrigante esforço daquela em significar a poesia de Frost a partir de sua relação com o espaço. Como evidencia Durão, a crítica percorre um longo e gradual trajeto de automatização do espaço que vai de sua dissolução enquanto instância geográfica, fundada na compreensão do espaço como representação de uma herança literária, passando pela mediação da consciência, e culminando na total perda de referencial espacial - momento esse em que o espaço incorpora a função da escrita. Em mais um bom exemplo da habilidade em articular um minucioso escrutínio do texto literário na forma de leitura cerrada atrelado a uma problematização teórica, Durão chama ainda atenção para as implicações do incorporar a função da escrita literária ao espaço na poesia de Frost, ao confrontá-la com o evidente arrefecimento do espaço ocupado pela literatura, através de sua comodificação, no contexto do capitalismo tardio. Dessa forma, encerra-se a seção com a constatação de que, face à conjuntura socioeconômica contemporânea, o status de incerteza adquirido pela literatura, e pela arte de modo geral, como se constata na interpretação do poema The Wood-Pile, firma-se tanto em sua existência quanto em sua resistência ao ser incorporada a qualquer espaço.

Sob o título "Ulisses in Four Figures of Coherence", o último capítulo do livro é dedicado a pensar as relaçôes entre negatividade e tempo, tendo agora como objeto de discussão a célebre obra de James Joyce, Ulisses. Mais uma vez, o exame que Durão faz dos diferentes momentos e reaçôes da recepção crítica da obra de Joyce revela que a lógica ordenadora da progressão linear do tempo, constitutiva dos discursos e práticas da cultura ocidental, encontra-se impregnada de forma ubíqua em todo gesto interpretativo. O escrutínio das mais diversas e díspares postulações hermenêuticas conferidas ao romance de Joyce desde sua publicação, - sejam elas tanto de orientação estruturalista quanto pós-estruturalista releva que toda tentativa de subversão da continuidade temporal, 
característica marcante em Ulisses, não escapa por sucumbir a uma lógica reguladora. Entretanto, uma leitura da negatividade aponta para uma dialética estabelecida pela tensão resultante da tentativa de confinamento da obra de Joyce a uma continuidade temporal, em oposição ao desejo desta em se lançar fora de tais limites para, por fim, abarcar o próprio tempo em que se desenvolve.

Ao final do livro, fica a certeza da relevância do trabalho de Durão e sua contribuição para área dos estudos literários. Entretanto, há ainda que se reiterar uma particularidade dessa obra em relação aos inúmeros manuais de teoria e crítica literária disponíveis no mercado editorial: a excelente articulação entre uma discussão teórica de profusão e o notável exame do texto literário ou, no caso, das diferentes obras que o livre propõe-se examinar; uma seara que as publicações especializadas raramente se arriscam a adentrar. $\mathrm{O}$ livro também nos convida a uma pausa para refletir sobre a forma quase impetuosa em que se dá produção, proliferação e o consumo de sentido, e a encarar de modo mais circunspeto os momentos e gestos de resistência e indeterminação do texto. Ademais, em uma época em que a exegese de textos literários encontra-se cada vez mais condicionada a uma infinidade de abordagens afiliadas a uma miríade de agendas político-sociais, Modernism and Coherence acena para a possibilidade de se pensar teoria e literatura em uma equação mais equilibrada, sem fazer de uma mero objeto da outra.

José Carlos Felix (UNEB) 